\title{
Judicialización constitucional de la política pública penitenciaria en Colombia ${ }^{1}$
}

\section{Constitutional judicial of prison public policy in Colombia}

Jimmy Soto Díaz
Candidato a magister en Derecho Público
Universidad Surcolombiana
jimmysotoabogado@gmail.com
María Eugenia Herrera Gutiérrez
Candidata a magister en Derecho Público
Universidad Surcolombiana
mariusiempre84@hotmail.com

\section{RESUMEN}

La profunda crisis penitenciaria, que desde hace varias décadas ha presentado Colombia, fue intervenida por la Corte Constitucional mediante un fallo histórico para el sistema, acudiendo a una nueva doctrina jurídica conocida como el estado de cosas inconstitucionales, con la pretensión de colectivizar los derechos invocados por los internos, en diferentes acciones de tutela o innumerables amparos individuales. En una muestra de su activismo judicial, el Alto Tribunal colombiano atendió la vulneración sistemática y reiterada de sus derechos humanos, vinculó a todas las entidades de la rama ejecutiva que hacen parte 0 influyen en el funcionamiento del sector penitenciario para, que en términos perentorios, le dieran una solución al problema. Este trabajo pretende determinar mediante métodos cualitativos, si la sentencia ha provocado la construcción de una verdadera política pública penitenciaria acorde al respeto de los derechos humanos de los internos, determinando sus repercusiones y desarrollos.

\section{PALABRAS CLAVE}

Estado de cosas inconstitucionales, cárceles, sistema penitenciario, políiticas públicas, política pública penitenciaria.

\section{ABSTRACT}

Deep prison crisis, which for decades has presented Colombia, was operated by the Constitutional Court in a landmark ruling for the system, going to a new legal doctrine known as unconstitutional state of affairs, pretending to collectivize the rights invoked by inmates, at different actions for protection or countless individual shelters. In a sample of his judicial activism Colombia's High Court heard the systematic and repeated violation of their human rights, linked to all agencies of the executive branch are part or influence the operation of the prison sector, to give him in peremptory terms a solution to the problem. This work aims to determine

1 A partir de la sentencia CConst T-153/1998, E. Cifuentes, hasta el año 2014. 
through qualitative methods, if the sentence has caused the construction of a real prison public policy according to the respect of human rights of prisoners, determining their impact and developments.

\section{KEYWORDS}

Unconstitutional state of affairs, prisons, correctional system, public policy, public policy penitentiary.

\section{INTRODUCCIÓN}

Este artículo hace parte de una investigación más amplia, la cual pretende determinar los verdaderos efectos administrativos e institucionales asumidos por el Estado colombiano ante la declaración del Estado de Cosas Inconstitucionales por parte de la Corte Constitucional, al que seguiremos refiriéndonos como $\mathrm{ECl}$, así como la reacción de las ramas del poder público en la construcción de una política pública, y la posición que sobre las medidas requeridas han asumido los diferente actores que integran el sistema, en ánimo de atender a una minoría, que a lo largo de la historia ha sido socialmente desatendida, y subvalorada en términos de derechos humanos, como lo es la población de internos pertenecientes a los establecimientos penitenciarios y carcelarios del país.

La jurisprudencia constitucional colombiana, ha desarrollado una tesis que se encuentra a la vanguardia del constitucionalismo latinoamericano, a partir de la importancia que tiene el juez constitucional dentro del desarrollo de la idea del Estado Social de Derecho en las recientemente reformadas democracias latinoamericanas. Colombia, aporta a dicha construcción, con la declaratoria de $E C l$, una nueva forma de ver el derecho, pues en ella hace la distinción entre lo que se espera de un Estado Social de Derecho y lo que realmente ese Estado Social de Derecho está dando a sus residentes.

Académicamente la mayor parte de los estudios se inclinan a revisar el grado de cumplimiento, de la sentencia T-025, 2004, que declaró el ECl sobre la situación del desplazamiento de la población colombiana afectada por la violencia o el conflicto, por lo que no deja de ser trascendental atender una investigación que indague los alcances de uno de los fallos que le dio forma y estructura a la doctrina del
$E C l$, y que contradictoriamente parece ser el menos eficaz. De esta forma, se pretende contribuir al reconocimiento de las principales incidencias no identificadas del $E C l$, en el diseño de la política pública penitenciaria, así como las alternativas que puedan garantizar en ella, los derechos fundamentales de los privados de la libertad.

Quienes se han detenido a estudiar la doctrina del $E C l$, como «técnica diseñada por el juez constitucional encaminada a garantizar la dimensión objetiva de los derechos inherentes al ser humano» (Vargas, 2003, p. 212), concluyen en la dificultad de fijar el grado de cumplimiento de las sentencias que han declarado el estado de cosas inconstitucionales. Por lo que este artículo se presenta como la introducción de un trabajo más amplio que pretende determinar, cómo ha reaccionado el Estado colombiano a partir de la sentencia T-153 de 1998, a través de sus actuaciones administrativas y legislativas, pero especialmente, si este ha promovido o no el diseño y ejecución de una política pública en el sistema penitenciario y carcelario del país. De igual manera pretende revisar si en su declaración y seguimiento, se han pasado por alto factores, o se han presentado tropiezos que impactaran el proceso de construcción y desarrollo de la misma.

\section{ESTADO DE COSAS INCONSTITUCIONAL COMO DOCTRINA JURÍDICA DE LA JUSTICIA CONSTITUCIONAL}

Para plantear el presente artículo, es necesario explorar unos breves antecedentes teóricos de la doctrina del ECl como categoría jurídica, para luego profundizar en la fiabilidad técnica de la misma en la eliminación de los comportamientos anticonstitucionales del sistema penitenciario y/o en la construcción de una política pública penitenciaria. 
Las primeras sentencias del $\mathrm{ECl}$, así como la propuesta de la figura en el derecho constitucional, corren por cuenta del entonces Magistrado Eduardo Cifuentes Muñoz, quien en sentencia SU-559 de 1997 enmarcó en la doctrina los derechos de la seguridad social, salud, trabajo y el derecho a la vida digna. Asimismo, el Magistrado Alejandro Martínez Caballero en ponencia de sentencia T-068 de 1998 reaccionó ante el alto número de acciones de tutela presentadas en contra de CAJANAL, declarando la ineficacia administrativa del Estado para resolver los derechos a la seguridad social de los jubilados, en contra de los fines de la función pública en un Estado Social de Derecho.

En este sentido, el Alto Tribunal no tardó en asumir la problemática penitenciaria, en la sentencia T-153 de 1998, siguiendo la misma corriente de colectivización de derechos y la crítica de ineficiencia administrativa, pero en especial, según Gómez (2012), sumado al manejo de la situación de los instrumentos de política económica del país, pues «desde el punto de vista constitucional, es imperioso destinar el presupuesto necesario para convertir las prisiones en centros donde los derechos fundamentales tengan vigencia» (p.51).

Para comprender el fenómeno de $\mathrm{ECl}$, es necesario profundizar seriamente en el origen de una figura jurídica relativamente joven para el derecho colombiano, por lo que es pertinente explorar las teorías que podrían haber dado origen al fenómeno, sin que estas requieran ampliación en este estudio, a excepción de la corriente latinoamericana que, inclusive, será objeto de mayor disertación en la investigación en curso².

\subsection{El activismo judicial de los Estado Unidos como insumo del ECI}

Esta corriente es propia del diseño constitucional norteamericano de protección de los derechos civiles de las minorías a través de sus precedentes judiciales, que tiene orígenes en el análisis e invocación de los argumentos de la Corte Suprema de
Justicia de los Estados Unidos, de sus «structural remedies» del caso Brown vs. Board of Education, en sentencia del 17 de mayo de 1954, considerada la piedra angular del activismo judicial norteamericano, que declaró que la leyes estatales que promovían la separación de estudiantes de raza negra y blanca negaban la igualdad educativa y, por consiguiente, violaban la cláusula sobre protección igualitaria de la decimocuarta enmienda de la constitución de los Estados Unidos, según lo cita Rodríguez (2011) al discernir sobre el impacto de esta escuela en los derechos socioeconómicos en América Latina, siendo que el ECl aborda casos estructurales y ordena medidas estructurales en un proceso de recuperación continua a suerte de la decisiones activistas de la Corte Constitucional de Colombia.

Las decisiones clásicas del activismo judicial de la Corte Suprema de los Estados Unidos, y otros fallos relacionados con la administración de las cárceles en ese país, seguramente fueron utilizadas como fuente para la creación de la doctrina del $E C l$, tal y como lo reconoce la misma Corte Constitucional colombiana (2003) en Sentencia T-1030-03, donde paradójicamente asumió el estudio de violación de derechos fundamentales por parte del sistema penitenciario colombiano, vinculando las características principales de fallos norteamericanos más famosos del activismo judicial norteamericano y aquellos sobre el manejo penitenciario en esa nación:

(...) 1) la acción procesal parte de la existencia de una violación sistemática de los derechos fundamentales de un grupo de personas y por ende la orden judicial apunta a modificar un status quo injusto; 2) el proceso judicial involucra a un conjunto importante de autoridades públicas; 3) los hechos expuestos guardan relación con políticas públicas; 4) la sentencia no tiene sólo efectos interpartes; 5) la Corte Suprema de Justicia conserva competencia para vigilar el cumplimiento del fallo; 6) el juez constitucional no es neutral o pasivo ante la situación y 7) la finalidad del fallo judicial es garantizar la

2 Tesis de maestría en Derecho Público, Universidad Surcolombiana. 
vigencia de unos principios constitucionales (CConst, T-1030/2003) [Subrayado fuera de texto].

El insumo de esta corriente a la doctrina del ECI se puede confirmar en la sentencia T-153 de 1998 de la Corte Constitucional colombiana, que al referirse a sus fallos precedentes en sentencias SU-559 DE 1997 y T-068 de 1998, expresó que:

(...) esta Corporación ha hecho uso de la figura del estado de cosas inconstitucional con el fin de buscar remedio a situaciones de vulneración de los derechos fundamentales que tengan un carácter general -en tanto que afectan a multitud de personas-, y cuyas causas sean de naturaleza estructural, es decir que, por lo regular, no se originan de manera exclusiva en la autoridad demandada y, por lo tanto, su solución exige la acción mancomunada de distintas entidades (CConst, T-153/98, E. Cifuentes). [Negrilla fuera de texto]

Sin embargo, a pesar de la notada influencia en doctrina del ECI no se profundiza aquí en esta corriente, pues para otros autores, ya ha sido objeto de reflexión como en el caso de Gómez (2010) en su trabajo de análisis sobre los motivos de la Corte Constitucional Colombiana para su declaratoria y Mora (2012). Ni tampoco se abordará la tesis de la dimensión objetiva de los derechos humanos, de origen alemán, pues finalmente terminaría subsumida por la corriente del activismo judicial norteamericano, pese a que ha sido objeto de vinculación a la doctrina del $E C l^{3}$.

\section{2. ¿Creatividad latinoamericana o influencia sudafricana?}

Esta otra tendencia, arraiga que la doctrina es propia de la creatividad de la Corte Constitucional colombiana, seguida por la Corte Suprema argentina, el Tribunal Constitucional peruano y sus pares ecuatorianos y bolivianos, a su vez influenciados por la Corte Constitucional sudafricana; preocupadas no solamente en declarar la violación de derechos sociales, sino en determinar parámetros y actuaciones específicas para superar los estados de cosas inconstitucionales o dificultades estructurales por parte de las autoridades responsables, instaurando procedimientos especiales de seguimiento para verificar que las autoridades cumplan las obligaciones genéricas contenidas en la sentencia (León, 2014).

Con relación a la Corte Constitucional sudafricana, particularmente han logrado «razonar sus fallos desde vertientes amplias, que incitan a un activismo de sus magistrados» [permitidos por sus superados antecedentes políticos de segregación racial, que han generado una cultura dirigida hacía la igualdad social y contra de toda clase de discriminación, y una constitución ${ }^{4}$ que permite una tutela judicial efectiva pues] (...) «el derecho a la protección juridiccional es una prerrogativa genérica que se encuentra sustentada en la Declaración Universal de Derechos Humanos (artículo 8) y, que la carta sudafricana retoma del principio jurídico: a todo derecho le corresponde un remedio judicial» (García, 2007, p.180 y 182).

3 En un sentido más amplio Vargas (2003) atiende el controversial rol del (...) «juez constitucional mucho más activo socialmente, más comprometido con la búsqueda de soluciones profundas a los problemas estructurales que padece nuestro Estado... un juez constitucional que no se limita a impartir justicia para casos particulares... sino que asume una verdadera dimensión de estadista, erigiéndose en un agente de cambio, adoptando decisiones de gran calado que trascienden la esfera de lo particular, cuya ejecución compromete la actuación coordinada de diferentes autoridades públicas... a fin de modificar una realidad social intolerable y contraria a los principios que informan el Estado Social de Derecho» (p. 206-207).

De conformidad con esta realidad, el juez no observa únicamente una dimensión subjetiva de los derechos fundamentales, en ánimo de proteger los derechos del individuo particularmente, sino que debe ubicar al mismo dentro de una comunidad vulnerable, que ostenta colectivamente los mismos derechos fundamentales, ubicándolos en un Estado Social de Derecho bajo la idea de protección plural de intereses generales en una dimensión objetiva «como el «deber ser» que corresponde a los derechos fundamentales en conjunto y a cada uno de ellos en particular, es decir, son principios objetivos que imponen mandatos de actuación y deberes de protección a todos los destinatarios de la Constitución...» (Tole, 2006: 258).

4 La nueva constitución de Sudáfrica, fue suscrita por Nelson Mandela el 10 de diciembre de 1996, coincidiendo con el día internacional de los derechos humanos, con vigencia desde el 4 de febrero de 1997, día en que fue distribuido en once lenguas como una muestra de la interculturalidad de la nación y del derecho a la igualdad previsto en su contenido (García, 2007). 
Al igual Liebenberg (2006), al referirse al potencial transformador de los derechos sociales por parte de los tribunales sudafricanos y las medidas enérgicas para garantizarlos, expresa en su investigación:

(...) los tribunales tienen a su alcance facultades suficientes para otorgar soluciones más eficientes en los casos de derechos sociales. Así, por ejemplo, los Tribunales pueden exigir que el Estado lleve a cabo un plan o programa que permita lograr los cambios necesarios y que adopte medidas y focalizadas conforme a dicho plan. En este contexto, el Tribunal debe ser capaz de superar su reticencia a ordenar medidas de supervisión con el fin de facilitar las reformas estructurales a largo plazo necesarias para la satisfacción de los derechos socioeconómicos. (...) Los Tribunales también pueden aliviar concretamente a quienes estén experimentando privaciones, evitando de ese modo daños irreparables a la vida, la salud y el desarrollo futuro. (p.64)

La notada influencia de la Corte Constitucional sudafricana en el derecho constitucional latinoamericano ha permitido avances significativos en el desarrollo de los derechos humanos, dados los antecedentes de violencia y discriminación que precedieron la expedición de la nueva constitución de país africano, la cual cuenta con una amplia carta de derechos y libertades que le ha otorgado el pasaporte a sus magistrados para trascender las fronteras de la desigualdad, e involucrar a las autoridades públicas en la construcción de un nuevo Estado, en su proceso de reconciliación social, paradigmático para el resto del planeta.

Sin embargo, con relación al origen de la doctrina de $E C l$, nos inclinamos por la posición que indica que ha sido influenciado en mayor medida por los antecedentes estadounidenses, que por el derecho constitucional sudafricano, dada la reciente creación del tribunal constitucional sudafricano, en relación al periodo de los primeros fallos que declararon el ECI en Colombia.

Respecto a Latinoamérica, en es esta investigación debe enfatizarse, por parte de la Corte Suprema de Justicia de la Nación Argentina, el caso «Verbitsky» con relación a la situación carcelaria del país, obligada a intervenir en la continua violación a las condiciones mínimas de detención, refiriéndose a un hacinamiento carcelario que se traduce en un trato inhumano y degradante para las personas privadas de la libertad.

El alto tribunal argentino ordenó a los poderes ejecutivo y legislativo de la provincia «a adecuar su legislación en materia de prisión preventiva, de excarcelación y de ejecución penal a los estándares constitucionales e internacionales» Mora (2012, pp. 10-11). En ese mismo caso, Mora en su estudio de litigios de reforma estructural, afirma que la Corte Argentina prescribió que la provincia de Buenos Aires le remitiera informes periódicos sobre las medidas adoptadas para mejorar la situación de las personas privadas de la libertad, y en efecto la excarcelación en el Código Procesal Penal de Buenos Aires fue modificada en marzo de 2006.

Además del caso colombiano, en el contexto latinoamericano es válido mencionar las experiencias propias del Perú, donde no solo su Tribunal Constitucional aplica la doctrina del $E C l$, sino que ha sido objeto de trasplante, según el editor de Figueroa (2013, p. 6), «por una de las providencias más emblemáticas emitidas en torno a la protección judicial de los derechos fundamentales», refiriéndose a la sentencia No. 00627-2009 de la Segunda Sala Civil del Cusco (2009) en la que declaró el estado de cosas ilegal, en el cálculo que hiciera la Dirección Regional de Educación del Cusco para liquidar la bonificación ${ }^{5}$ que reciben los profesores por los años

\footnotetext{
5 En Colombia estas bonificaciones, son las conocidas vulgarmente como quinquenios. Siendo asignaciones extraordinarias que en el Perú son recibidas por un profesor cuando cumple 20, 25 o 30 años de servicio al Estado, debiéndose liquidar con base a su remuneración total o íntegra, pero la Unidad de Gestión Educativa Local las liquidaba en función de su remuneración total permanente. Estos procesos contencioso administrativos fueron iniciados por profesores en repetidas ocasiones, en un trámite de 18 a 24 meses de duración, sin contar el término de ejecución, lo que hizo reprochable para las Salas Civiles, quienes en repetidas oportunidades habían reiterado como debía liquidarse la bonificación, que un profesor deba sumir gastos para reclamar un derecho ya establecido
} 
de servicios que prestan al Estado sobre la base de la remuneración permanente, en vez de la remuneración integral o total. En tal declaración se encuadró una tutela preventiva en el trámite de un proceso contencioso administrativo en sede constitucional, estableciendo la posibilidad de que un profesor en homogénea situación a la del demandante en este proceso, pueda acudir ante el mismo juez, solicitando la declaración de homogeneidad y posterior represión del acto homogéneo al declarado ilegal (Figueroa, 2013, p. 329).

Con el anterior caso, se justifica destacar el amplio espectro de la creatividad de la Corte Constitucional Colombiana y de los otros países Latinoamericanos en la adopción del $E C l$, enfatizando como el Tribunal Constitucional peruano (2005), en sentencia No. 3149/2004 AC/TC, otorga a Colombia su original paternidad:

Este Tribunal en el caso Arrellano Serquén contra el Consejo Nacional de la Magistratura, utilizó la técnica de la declaración del Estado de Cosas Inconstitucional, desarrollado de manera creativa por la Corte Constitucional colombiana, con el objeto de expandir los alcances de la sentencia en un proceso de tutela de derechos fundamentales con efectos, prima facie, inter partes, evitando que otros ciudadanos afectados por los mismos comportamientos violatorios tengan que interponer sucesivas demandas con el fin de lograr lo mismo.

Con la declaración de una situación determinada como contraria a los valores constitucionales (Estado de Cosas Inconstitucional), se generan una serie de responsabilidades de parte de los órganos, instituciones o personas concretas involucrados en los actos vulneratorios, permitiendo, de este modo, allanar el camino en la búsqueda y satisfacción de los derechos comprometidos. Así lo dejamos establecido en el caso Arrellano Serquén, precisando que: «(...) esta técnica, en un proceso constitucional de la libertad, comporta que, una vez declarado el "estado de cosas inconstitucionales", se efectúe un requerimiento específico o genérico a un (o unos) órgano(s) público(s) a fin de que, dentro de un plazo razonable, realicen 0 dejen de realizar una acción u omisión, per se, violatoria de derechos fundamentales, que repercuta en la esfera subjetiva de personas ajenas al proceso constitucional en el cual se origina la declaración.» (TribConstPerú, 2005, Exp.No.3149/2004 AC/TC, Bardelli, Gonzales y Vergara).

En Colombia, la doctrina del ECl se ha desplegado igualmente a lo largo del Poder Judicial, al punto que el Tribunal Superior de Medellín (2013), en virtud de una acción de tutela que denunciaba las condiciones infrahumanas de un recluso, y de otros a los que resolvió representar, de la Cárcel Bellavista y de anexos psiquiátricos de otros establecimientos de reclusión del país, resolvió declarar la «persistencia agravada del estado de cosas inconstitucional» (p.111), que fuera declarado por la Corte Constitucional en 1998, al interior de Establecimiento Penitenciario y Carcelario de Medellín Bellavista. Con lo que puso nuevamente en jaque al Estado, y con lo que asumimos, se hizo llamado de atención a la Corte Constitucional colombiana para que revise o unifique su doctrina del ECl para el sistema penitenciario, para potencializar sus efectos en favor de los privados de la libertad, que hoy la lleva a enfrentar un nuevo estado de cosas contrario a la constitución (CConst, T-388/2013, M.V. Calle).

Lo cierto es que, tanto el activismo judicial norteamericano como la creatividad judicial latinoamericana, advierten una intervención judicial que ha generado una interdependencia entre el derecho y las políticas públicas, fomentada en el rol asumido por los tribunales judiciales de exhortar o conducir al Estado en la creación, sustitución, modificación de reformas estructurales. Esto ocurre al no ser posible que estas políticas públicas se originen como es normal, en la concertación coherente y participativa de propuestas, soluciones $y / 0$

legalmente a su favor (Figueroa, 2013). La novedad de la decisión se advierte por su concepto de justicia distributiva, en el marco de una tutela preventiva, adoptado en un procedimiento contencioso-administrativo que no está directamente vinculado a la garantías constitucionales del artículo 200 de la Constitución Política del Perú de 1993 (Landa \& Velasco, 2014, p. 97-98). 
estrategias, frente a un asunto de interés público que afecte o pueda afectar a una comunidad determinada, que contengan decisiones y acciones por parte de las autoridades públicas.

En todo caso, ambas corrientes obedecen a la tensión propia entre un constitucionalismo garante de las minorías, y la democracia como instrumento de las mayorías; correspondiéndole al constitucionalismo, ser el promotor del respeto de los derechos de las minorías, que no es posible a través de la leyes o actuaciones administrativos, generando así procesos de formación de políticas públicas, especialmente suscitados por el Poder Judicial reconocido doctrinalmente como un juez de las políticas públicas, para decirlo con Gómez (2012).

Esta corriente, no desconoce las palabras de López (2011):

Ahora la estricta división de poderes o funciones del Estado viene aparejada con una mutua cooperación pero con independencia y autonomía de cada una de ellas; el ejecutivo ha perdido su gran poderío y la rama judicial ha entrado a jugar un papel protagónico en el nuevo esquema; la seguridad jurídica ha tenido que ceder ante los principios básicos de igualdad y justicia; el legislador ha debido someterse a los parámetros establecidos por la Constitución y su intérprete oficial, la Corte Constitucional; el imperio de la ley ha caído y hemos entrado en el imperio de la Constitución, la cual tiene aplicación directa sin necesidad de una ley regulatoria, específicamente en temas de derechos fundamentales. (p.193).

\section{EL ECICOMO TÉCNICA PARA ELIMINAR COM- PORTAMIENTOS ANTICONSTITUCIONALES DEL SISTEMA PENITENCIARIO}

El profesor Henao (2013) señala la existencia de un déficit de gobernanza que se traduce en un vacío de poder, que para el caso penitenciario se ajusta particularmente, teniendo en cuenta la transgresión masiva y sistemática de los derechos humanos; es así como se autoriza la injerencia de la Corte Constitucional colombiana en asuntos de competencia de otros poderes públicos, ante las reiteradas acciones ciudadanas (de internos y familiares) frente a las repetidas violaciones de sus derechos, sin solución por parte de las autoridades responsables de resolverlos, legitimando la intervención judicial en las políticas públicas, por la carencia y falta de desarrollo de las misma por parte del Estado.

La ausencia de una política pública en materia penitenciaria, de la mano con la ambigüedad de una política criminal del país, que tiende por aumentar las penas y los delitos existentes, con la inevitable consecuencia de crecimiento de la población carcelaria, ha terminado por afectar reiteradamente los derechos fundamentales de los internos en las cárceles colombianas. Por ello es que se asegura que la Corte Constitucional colombiana, en un intento original de intervenir el problema, generó la doctrina del $\mathrm{ECl}$ como una nueva categoría jurídica para colectivizar el amparo de los derechos fundamentales, y como garantía constitucional ante las numerosas demandas de tutela formuladas por los reclusos en los establecimientos penitenciarios y carcelarios del país, ante las reiteradas y sistemáticas violaciones a sus derechos humanos.

Este tipo de decisiones de la Corte Constitucional colombiana han sido duramente criticadas, en términos de Castaño (2013), al intervenir el proceso natural de formación de las políticas públicas, por la falta de información ${ }^{6}$ que los jueces tienen para decidir los grandes problemas estructurales del Estado, excluyendo a los demás actores sociales, políticos e, inclusive, librándolos de la responsabilidad política de sus omisiones o desaciertos. Por otro lado, la Corte es censurada por ser considerada un nuevo

6 Según Castaño (2013), «los jueces pueden llegar informarse de manera suficiente antes de tomar una decisión; es más, el sistema legal prevé dicha situación y permite a los jueces acudir a auxiliares de la justicia, como lo son los peritos que sirven para ilustrar al operador judicial a fin de que tome sus decisiones con información suficiente; sin embargo, los costos de obtener dicha información para una Corte son más altos que para una entidad especializada en la materia de que trate el problema planteado». 
actor de distribución de la riqueza, sin entender que ese activismo hace parte de su rol progresista del juez que todo lo puede defendido por Dworkin en cabeza de los «interpretativistas moderados» (Castaño, 2003, p. 128-129). Otro defensor del papel progresista de la Corte es López (2004), quien en su visión filosófica del derecho argumenta:

Hart, Dworkin y Alexy brindaron las ideas más abstractas para fundamentar una metodología judicial alternativa propicia para el desarrollo de los principios y derechos constitucionales; estos mismos autores ofrecieron insumos para justificar un aposición antiformalista (pero en todo caso objetivista) en el análisis jurídico que interpretaba la constitución de manera pluralista y progresista. Por estas razones, el nuevo derecho terminó argumentando a favor del principio de vinculatoriedad de la doctrina constitucional, del antiformalismo metodológico presente en autores como Dworkin y Alexy, finalmente, de los resultados progresistas en materia sustantiva (p. 456-457).

En términos de política económica, la judicialización de las políticas públicas ha implicado un alto costo financiero, en el afán de desplegar las ordenes de la justicia constitucional. El caso penitenciario, no es la excepción. Para esto, el país cuenta con dos opciones, la primera asumir el alto costo de financiación de una infraestructura carcelaria y administrativa que lo convierta en un sistema eficiente, sumada a la imposición de medidas que garanticen una sostenibilidad financiera permanente para su funcionamiento, coherente con el cumplimiento de los fines del Estado Social de Derecho. La segunda, ahondar en la búsqueda de opciones que minimicen el costo del sistema penitenciario y carcelario, explorando alternativas en la Política Criminal del Estado.
En el primer caso la Corte advierte la necesidad de hacer reducciones en otros campos, los cuales impondrían sacrificios sociales no desproporcionados sobre los demás ciudadanos, que en principio sonó como una propuesta que legitimó al gobierno para adelantar inversiones significativas en la infraestructura del sistema, pero que en realidad se trataba de una intervención del Alto Tribunal en el ejercicio del gasto público, a lo que el gobierno le ha salido al paso para neutralizar los efectos de su intrusión ${ }^{7}$, dados los altos costos financieros para el Estado. Esto sucede rescatando el ejercicio constitucional de regulación económica por el juez constitucional, al exigir la eficiencia en la sostenibilidad del sistema e inversión en beneficio del gasto social, para obtener una política pública económica sostenible, en criterio de Gómez (2012).

Es así como la Corte propuso la edificación de nuevos establecimientos carcelarios, que en efecto se han construido, y se siguen construyendo, sumado a la ejecución de proyectos de ampliación de cupos en las cárceles que permiten el crecimiento de su estructura, en la intención de ampliar la capacidad carcelaria para atender la actual superpoblación, ordenando al Estado colombiano la ejecución de un plan de construcción y refacción carcelaria, omitiendo y desconociendo estrategias u otras medidas que hubieran aliviado estructuralmente la crisis penitenciaria, desestimando una oportunidad histórica de cambiar el rumbo a la situación carcelaria del país, incurriendo en una posible falla en la aplicación del ECl como técnica para eliminar los comportamientos anticonstitucionales del sistema penitenciario al no ofrecer un reforma estructural, a la sumo por no afectar el equilibrio de poderes respecto a sus límites, y competencias propias del poder ejecutivo y legislativo. Además reflejó en su decisión y

7 El Congreso de la República de Colombia expidió la Ley 1695 de 2013, que permite adelantar el incidente de impacto fiscal por cualquiera de sus Ministros sobre sentencias o autos de los altos tribunales, cuyo trámite será obligatorio para estas corporaciones. Sin embargo, la declaración del ECl en el sistema penitenciario, cuenta con la ventaja debe haber sido declarado antes de la promulgación de esta ley. Este incidente puede ser visto como un instrumento de conciliación presupuestal entre el poder judicial y los poderes ejecutivos, o para los más pesimistas; como una cortapisa a la judicialización de las políticas públicas y a la intervención de los jueces en los aspectos propios de otras autoridades públicas.

La Corte Constitucional colombiana (2014) en sentencia C-870-2014 declaró condicionalmente exequible la procedencia del incidente de impacto fiscal sobre las sentencias y autos proferidos en el marco de acciones de tutela. 
seguimiento, poca conciencia de su potencial e importante intervención en la generación de una política pública penitenciaria, cuyos avances parciales se deben en gran medida a su legítima intrusión. Para puntualizar, aquí se puede recordar a Henao (2013) quien también sostiene:

La Corte se limitó, en efecto, a ordenar lo que ya mencionamos, pero no estableció ninguna relación entre estos hechos y lo ordenado en la sentencia T153 de 1998. Por tanto, flaqueó en un elemento trascendental en las políticas públicas: la evaluación y la retroalimentación.

El hacinamiento en las cárceles colombianas aún no se ha superado. Pero debido a que la Corte se pronunció al respecto y fue gestora de la política pública, esa situación se hizo más visible. En los años siguientes se hicieron esfuerzos presupuestales para adecuar y construir nuevos establecimientos penitenciarios y carcelarios.

\section{EFECTOS DEL ECIEN LA CONSTRUCCIÓN DE UNA POLÍTICA PÚBLICA PENITENCIARIA Y ALTERNATIVAS NO PREVISTAS}

Para determinar la existencia o evolución de una política pública penitenciaria es necesario referenciar según Muller (2010) una «imagen de la realidad sobre la cual se quiere intervenir», siendo necesario representar la problemática, identificar las soluciones y definir las propuestas de acción, cuestionarse "¿a través de cuáles procesos sociales, políticos o administrativos se toman las decisiones que constituyen las políticas públicas?» "¿cómo funciona el sistema de organizaciones públicas, a través del cual se elabora y se pone en marcha una política pública?» Por último, si esta se encontrara al menos en parte diseñada: «¿cómo medir o evaluar el impacto de una política pública en el campo social y económico?» (pp. 115; 150).
Si bien es cierto la Sentencia T-153 de $1998^{8}$, fuera de declarar el $E C l$, intervino en la generación de una política pública penitenciaria lo hizo principalmente en seis aspectos ${ }^{9}$; el primero, el plan de construcción y refacción carcelaria ordenándole al Estado el presupuesto necesario a partir 1998 y las vigencias fiscales futuras; segundo, recluir a los miembros de la fuerza pública en establecimientos especiales; tercero, separar completamente a los sindicados de los condenados; cuarto, solucionar las carencias de personal especializado en las prisiones y de la Guardia Penitenciaria; quinto, ordenar a gobernadores y alcaldes crear y mantener centros de reclusión propios y, sexto, ordena al Estado tomar las medidas necesarias para garantizar el respeto de los derechos fundamentales de los internos en los establecimientos de reclusión del país.

De una primera lectura, de los seis aspectos mencionados, se nota la ausencia de acciones y estrategias que pudieron ser objeto de intervención, y que podrían ser la explicación del posible fracaso de la aplicación de ECl en materia penitenciaria; pero especialmente no se profundizó en la protección y promoción de los derechos fundamentales por parte de los agentes del sistema penitenciario, ni en otras soluciones 0 alternativas para atenuar el impacto del hacinamiento o superpoblación carcelaria, ni se exhortó a las autoridades legislativas y ejecutivas a tomar las medidas que resolvieran el problema estructural de la crisis carcelaria; estas estrategias serán objeto de medición en un estudio más amplio, que viene siendo adelantado en la maestría de Derecho Público de la Universidad Surcolombiana, por los mismos autores de este artículo.

Entonces, al no existir un clara intervención de la Corte Constitucional colombiana en el diseño de una política pública, es incierta la necesidad, importancia y urgencia de la misma, con la particularidad de que el proyecto de una política pública no sea

8 Op. cit. CConst, T-153/98.

9 Lo demás aspectos ordenados, no se relacionan, o no tienen trascendencia en la generación de una política pública penitenciaria, pues se trata de aspectos que pretendía resolver situaciones concretas relacionadas con los accionantes. 
exitoso, mientras no sea alimentada en gran medida por las garantías a los derechos humanos de la población reclusa, una minoría sometida a la especial sujeción de Estado, y con la que Colombia está en deuda durante hace ya varias décadas. Al respecto, llegó a afirmar Restrepo (2006):

En significado, las políticas públicas son en sí mismas un escenario de lucha por la democracia, la justicia, la solidaridad, la igualdad y la libertad. A la vez que requieren de estos principios para existir, contribuyen para la construcción y sostenimiento permanente de ellos (p. 43).

Sin embargo, aquí se abandona el criterio de Restrepo (2006) al pretender tratar a las políticas públicas como expresiones democráticas de las mayorías, cuando en gran medida, las mismas deben garantizar el respeto y protección de las minorías no representadas. Por lo que a pesar de las críticas, vale la pena subrayar el papel asumido por la Corte Constitucional frente al Estado, en representación de los derechos de las minorías más débiles, en cumplimiento de su deber constitucional y «que por sus condiciones físicas, mentales, de debilidad manifiesta o mera vulnerabilidad requieran de una excepcional consideración por parte del Estado» (Rodríguez, 2005, p. 341).

Lo anterior indica, la existencia de una representación judicial por parte del Tribunal Constitucional Colombiano de unas minorías consideradas sujetos de especial protección, las cuales adolecen de una verdadera representación política y social, por lo que en ejercicio de la cláusula contra-mayoritaria ${ }^{10}$ promovida por el neoconstitucionalismo se resuelve intervenir el problema mediante remedios estructurales para generar los alivios necesarios para superar la situación. Pero los remedios en gran medida no han sido suficientes, o inclusive equivocados, en el tratamiento de la crisis institucional del sistema carcelario, sujeto de permanente observación en razón de la reiterada y continuada violación de los derechos humanos de los reclusos.

Es así, que una política pública penitenciaria está obligada a contener un alto grado de ingredientes de protección y promoción de derechos fundamentales al interior de los establecimientos de reclusión, lo que en ocasiones no es bien recibido por algunos actores o sectores endógenos y exógenos del sistema, sumado al contraste político y socioeconómico del Estado. En esta situación, Alexy, R. (2003) a referirse a Böckenförde en Staat, Verfassung, Demokratie advierte que:

(...) las decisiones sobre los derechos fundamentales representan al mismo tiempo decisiones sobre la estructura fundamental de la sociedad, la discusión sobre tales derechos tiene en una amplísima medida implicaciones políticas. Esta circunstancia aclara por qué el problema de la interpretación de los derechos fundamentales no puede ser objeto de reflexiones serenas, y en cambio sí un elemento que aviva las disputas en la arena política. (p. 35).

\subsection{Desvíos y desafíos de la política pública pe- nitenciaria en Colombia. El «estado de cosas de sistema penitenciario»}

El Ministerio de Justicia de la República de Colombia (2014), publicó el proyecto de fortalecimiento y seguimiento a la política penitenciaria en Colombia, a través de un informe de lineamientos para el fortalecimiento de la política penitenciaria en Colombia, en el que reconocen como punto de partida de la politica pública penitenciaria la Sentencia T-153 de $1998^{11}$, la cual según ellos, impulsó principalmente un plan de construcción y refacción carcelaria, que en criterio de los autores del proyecto no ha sido suficiente para superar los condiciones críticas de los privados de la libertad. Sin embargo, el estudio pierde su norte, olvidando que se trata de un primer

10 Este poder que a través de los jueces se les da a las minorías que requieren de una especial protección, es apenas entendible desde el punto de vista de que como se ha señalado lo que se pretende es brindar una sobre protección que a las personas que se han quedado sin la representación debida, para que no sean avasalladas por las decisiones que se lleguen a tomar por los encargados de realizar las leyes (Gama, 2012).

11 Op. cit. CConst, T-153/98 
acercamiento a la solución estructural del problema, y un primer diseño de política pública penitenciaria, al pretender efectuar desde los primeros ejes del proyecto, enfoques de tratamiento diferencial sobre la población reclusa como una de las preocupaciones de su diagnóstico y recomendaciones de estudio. Por ejemplo, el abordaje prioritario del tratamiento diferencial para la población indígena, entre otras minorías reconocidas por el Código Penitenciario y Carcelario. Aunque no pretendemos desestimar la importancia del enfoque diferencial como parte de la progresividad de las posibles estrategias que se requieran, se deben atender con mayor preocupación otros componentes del universo penitenciario, en atención a una metodología deductiva, sin pretender que solucionando las particularidades podamos resolver el padecimiento principal.

Tampoco es clara la participación de todos los actores que integran el mundo de lo penitenciario y carcelario $^{12}$, pues en lo que respecta a esta etapa es fundamental determinar e identificar con claridad quienes están llamados a participar de esta primera fase. Sería equivocado estructurar una política pública penitenciaria sin la abierta participación de los beneficiarios e interesados en la misma; entre otros, los privados de la libertad, sus núcleos familiares o visitantes, Organizaciones No Gubernamentales (ONG) defensoras de los derechos humanos, funcionarios penitenciarios (administrativos y guardia penitenciaria), entidades territoriales, rama judicial, organismos internacionales, congresistas y demás autoridades públicas del sistema penitenciario y carcelario, entre otros. Pues no se trata de concertar propuestas con la sociedad civil en general, sino de dirigir las discusiones con una población particular interesada y conocedora de las posibles soluciones y estrategias para atender la situación carcelaria, sin perder de vista en todo momento que la política pública penitenciaria, debe estar centrada en la garantía de los derechos humanos, dentro del marco razonable de la seguridad, y los estándares internacionales de las buenas prácticas penitenciarias.

Por otro lado, es acertado que el Ministerio de Justicia y del Derecho (2014) haya determinado con mucha lucidez, la pertinencia de la política pública penitenciaria para el Estado Social de Derecho, entendiendo, que una de las importantes «discusiones sustanciales que se derivan de la Política Penitenciaria es su relación con la política criminal. Resulta imposible la Política Penitenciaria como el ejercicio de una función desarticulada del Sistema Penal y, por lo tanto, independiente de la política criminal» (p. 17). Sin embargo, no se profundiza claramente en los aspectos propios de esta relación, pese a que el proyecto fue dirigido por la Dirección de Política Criminal y Penitenciaria de ese Ministerio, con excepción de la propuesta de racionalización de la penas en todas las fases; legislativa, judicial y penitenciaria, así como la política reactiva, incoherente y fuertemente punitiva colombiana en términos del mismo Ministerio de Justicia y del derecho.

No deja de llamar la atención, que ese Ministerio en 2014, representó en su estudio el actual «estado de cosas del sistema penitenciario» (p. 25), al desplegar su diagnóstico de la política penitenciaria en Colombia en contraste con el ECl, como si ese estado de cosas ya no fuera inconstitucional, o ya no existiere un problema estructural del Estado por la continua, reiterada y masiva violación de los derechos fundamentales de la población penitenciaria. Las afirmaciones en este sentido, desconocerían los esfuerzos comunes en superar la crisis estructural del sistema.

\subsection{Revisión de la política criminal y políticas antidrogas como solución al hacinamiento carcelario}

Según la Universidad de los Andes (2010), en un informe sobre la situación carcelaria en Colombia,

12 El Ministerio de Justicia y del Derecho (2014), expresa que en una primera etapa de diagnóstico, fueran socializados algunos aspectos con actores de la política penitenciaria [que no relaciona], expertos y la sociedad civil [sin especificar] en cinco ciudades del país, entre noviembre y diciembre de 2014. 
es innegable que el hacinamiento es uno de los factores que afectan el sistema, siendo inquietante reconocer que a pesar de la constante ampliación de los cupos carcelarios no ha sido posible para el Estado controlarlo, o veces ni siquiera mitigarlo. Algunas de las fallas en la política criminal fueron identificadas en la sentencia T-153 de $1998^{13}$, pero finalmente no influyeron en las órdenes o remedios estructurales que debió impulsar la Corte Constitucional colombiana, pese a sus demostraciones pasadas y recientes «en poner límites claros a los poderes legislativo y ejecutivo (...) atendiendo las demandas de los ciudadanos que recurren a la administración de justicia para satisfacer las necesidades de políticas públicas» (Castaño, 2013, p. 136$)^{14}$.

La Corte optó por no invadir los espacios propios de la política criminal, pues pudo exigirle al Congreso de la República de Colombia la revisión de las normas penales referentes a la detención preventiva y la excarcelación, para lograr una verdadera aplicación excepcional de la medidas intramurales, en el ejercicio del derecho a la presunción de inocencia, y el debido proceso penal, así como la tipicidad de algunas conductas, las penas y la dosificación penal de las misma, la cual puede considerarse el factor más influyente en la sobrepoblación carcelaria del país, pues no todo reproche penal debe traducirse en una condena efectiva en prisión, más si se tiene en cuenta que hemos estado ad portas de convertirnos en un Estado fallido en materia carcelaria.

A estos aspectos, se aproximó Tocora (1997), al estudiar el inflacionismo penal, la política criminal reactiva, ahora conocido como populismo punitivo y al proponer la despenalización del consumo de drogas. Este último aspecto fue demostrado en una reciente investigación de Uprimny, Guzmán \& Yepes (2013) en la que concluyen:

(...) «que la judicialización de los delitos de droga en Colombia es muy problemática desde el punto de vista de un valor esencial a los derechos humanos y al Estado de derecho, que es el principio de proporcionalidad penal, según el cual toda medida punitiva tiene que guardar una razonable proporcionalidad entre la intensidad y severidad del castigo y el daño que se busca prevenir» (p. 119).

En este sentido una política pública penitenciaria debe presionar a los responsables de la política criminal para que rápidamente revisen los errores de la misma, pues de considerar en mantenerla deberán optar por garantizar la implementación de instrumentos de política económica y fiscal que garanticen el funcionamiento de un sistema insostenible, dado el constante crecimiento de la población carcelaria en Colombia.

No sería improbable que la Corte Constitucional colombiana en su invocada y esperada intervención de las políticas públicas, avanzara en la revisión de las políticas antidrogas, así como en su momento lo hiciera en aspectos como la dosis personal y otros afines, como efectivamente lo ha hecho, dado lo anticuado y vetusto del parlamento colombiano. En palabras de López y Gómez (2014) se ha dicho que:

Colombia es el único caso, a diferencia de otros países de América latina, en el cual la despenalización de la droga se ha dado por vía judicial. Se critica que una Corte de 9 magistrados no elegidos democráticamente, haya decidido un asunto que debió haber sido discutido en el foro natural de la democracia, es decir el Congreso de la República.

13 Op. cit. CConst, T-153/98.

14 Castaño advirtió en 2013, que la Corte Constitucional colombiana podía regular esto límites de control al Congreso o al Gobierno, como tradicionalmente lo ha hecho, haciendo referencia a la exhortación de la Corte Constitucional colombiana (2009) al Congreso para regular materias con el fin de garantizar los derechos de las parejas del mismo sexo, pues encontró que hay un déficit de protección por ausencia de regulación de la materia. En sentencia C-577-2011, que resolvió la demanda de inconstitucionalidad del artículo 113 del Código Civil otorgó un plazo de dos años al Congreso para regular la materia, de lo contrario se aplicarían todos la reglas del matrimonio heterosexual.

Vale la pena destacar, que el Congreso votó negativamente el proyecto de Ley que pretendía legalizar el matrimonio homosexual en abril de 2013. 
Sin embargo, dado el desprestigio de este órgano de representación popular, el ciudadano del común ve con buenos ojos la intervención de la Corte en esta discusión y en la mayoría de asuntos políticos, jurídicos, sociales económicos del país, lo cual constituye un verdadero desafío para la democracia colombiana.

Esta opción, indiscutiblemente ha ingresado al debate nacional e internacional, en la medida en que se siga comprobando el fracaso de la guerra contra las drogas, aunado a su alto costo social y económico de la política antidroga. Por lo que merecerá ser objeto de una mayor discusión por generaciones presentes y futuras, en el contexto de la actual globalización y sus realidades. Pero siempre será un debate modulado por los Estados Unidos, quien ya viene dando los primeros pasos hacía la legalización por vía del consumo medicinal y recreativo del cannabis.

\subsection{Derecho al sufragio de todas las personas privadas de libertad}

Quien diera una mirada desprevenida con relación al derecho al sufragio de los reclusos en Colombia, no advertiría en la restitución de esa prerrogativa una solución a la crisis penitenciaria y carcelaria del país. Pero aquí es válido destacar que los privados de la libertad no cuentan con una representación social efectiva ni una representación política que les permita acelerar el proceso de dignificación e igualdad ${ }^{15}$ de derechos que actualmente reclaman, pese a que se encuentran enmarcados como sujetos de especial protección para el Estado, condición que no ha sido suficiente como garantía de defensa 0 auxilio de sus derechos sociales, siendo más conveniente enmarcarlos en un concepto amplio de minorías.

En este sentido, Filippini y Rossi (2012), afirman que:

(...) la política estatal que impide el ejercicio del derecho al voto a aquellas personas que se encuentran condenadas impacta directamente sobre un sector de la población compuesto de un modo comprobadamente preponderante por individuos pertenecientes a grupos económica y socialmente relegados, cuya situación de vulnerabilidad incluso ya ha sido agravada por el propio Estado. Ello justifica considerar a la práctica estatal como un trato discriminatorio, que potencia la desigualdad que estos individuos sufren respecto al resto de la población (p. 198).

Si bien es cierto estas personas, se encuentran subordinados a pena de prisión o medida privativa de la libertad, en el contexto de un Estado Social de Derecho, no es coherente que deban soportar ser doblemente castigados por un sistema penitenciario y carcelario fallido que no les proporciona las condiciones mínimas de resocialización, habitación, sanidad, salud, unidad familiar, y demás derechos propios de la dignidad humana, su ausente representación ha sido asumido en nuestro constitucionalismo por el Poder Judicial, el cual ha dado una dura batalla en la reivindicación de los derechos de esta clase de personas, a través de innumerables fallos de tutela en juzgados y tribunales, alguno de ellos objetos de revisión y profundización por parte de la Corte Constitucional.

Sin embargo, a pesar de la declaratoria del $E C l, y$ de otras importantes sentencias en sede de revisión por el alto Tribunal Constitucional colombiano, se deben explorar alternativas desde las instancias judiciales, sociales, políticas, de opinión, o inclusive a instancias de organizaciones o tribunales de justicia internacional para que se generen alivios a través de remedios estructurales en mora de ser recibidos por un sistema en estado terminal. Una de estas estrategias sería la restitución del derecho a sufragio a favor de las personas privadas de la libertad.

En Colombia los privados de la libertad en su condición de sindicados son sometidos a pena accesoria consistente en inhabilidad para el ejercicio

15 Sin perder de vista que sus derechos pueden ser suspendidos o restringidos, pero entendiendo que la mayoría de sus derechos se conservan plenamente. 
de derechos y funciones púbicas, lo que conlleva a considerarlos no aptas para participar en los procesos electorales locales, regionales y nacionales; sanción penal que no tiene mayor efecto social ni individual, pues poco o mucho le importa a la sociedad que los reclusos participen en los las elecciones populares, pero que para los internos de los establecimientos carcelarios y penitenciarios, sería la oportunidad de elegir (más no de ser elegidos) a aquellos que se comprometan a representar su intereses en ejercicio de las funciones; sólo así, alcaldes, concejales, gobernadores y diputados, se comprometerían en mayor medida a gestionar o asignar recursos para la operación sistema penitenciario y carcelarios, toda vez que los mismos obedecen a los mandatos populares de sus propios electores, no sintiéndose obligados a atender aquellos que no pueden ejercer el voto popular.

Si bien existen otras minorías o sujetos de especial protección que no pueden sufragar, debemos insistir en que esta población se encuentran sometidos a una sistemática y reiterada violación de sus derechos humanos, que no han sido superados, y que es urgente que conciban alivios a través de estrategias que no generen altos $\operatorname{costos}^{16}$ financieros para el Estado, pues el mismo ha fracasado en su esfuerzo por resolver la situación. En favor de este discurso, Dhami (2009) argumenta:

La privación del sufragio, sin embargo, sirve para aumentar la distancia social entre el delincuente y la comunidad, y reafirma sus sentimientos de alineación y aislamiento. Esto puede impedir, de su parte, la aceptación y el respeto de las normas sociales y el imperio de la ley. La privación del sufragio también etiqueta negativamente a los ciudadanos «de segunda clase». En una encuesta a 33 criminales condenados en Estados Unidos, Uggen y Manza encontraron que la privación de sufragio fue estigmatizador y un signo de aislamiento social, incluso si las personas no habían ejercido su derecho al voto en el pasado. Los criminales dieron cuenta de la necesidad de sentirse como ciudadanos plenos. El estigma y la humillación de que se les niegue el derecho a votar, puede ser perjudicial para la adquisición de esta imagen de sí mismo. (...) Tal etiquetamiento puede llevar a nuevas actividades delictivas (pp. 131-132) ${ }^{17}$.

En efecto, a pesar de que el no condenado puede ejercer su derecho al voto, en la práctica este se ejercicio no se concreta debido a múltiples factores, como lo es la retención de la cédula de ciudadanía por las autoridades militares, de policía, penitenciarias, o inclusive su grupo familiar ${ }^{18}$. Cuando no ocurre alguna de estas circunstancias, por razones de la jurisdicción electoral es casi imposible que ejerzan su derecho al sufragio, por cuanto son capturados o trasladados a otras jurisdicciones diferentes a la que se habían inscrito, o en ocasiones la ubicación del penal se encuentra en un municipio distinto al de la mayoría de inscritos para votar, por encontrarse a las afueras de la ciudad. Estas dificultades no son de preocupación de las autoridades, por el mismo rechazo y olvido social que generan este tipo de personas, lo que hace que estos imputados vean suspendido sus derechos civiles sin haber sido condenados, en contravía del principio de presunción de inocencia.

Con lo que no cuentan, los que han omitido o negado esta iniciativa de restitución del sufragio electoral, es que detrás de cada interno hay grupos sociales, personales, y familiares dispuestos a apoyar propuestas de representación política, que en caso de

16 En Colombia ya existe un rubro presupuestal y una estructura para que los privados de la libertad participen en las elecciones populares, pero la participación es mínima debido a las razones expuestas en el presente capitulo. Es por ello, que no se incurriría en mayores inversiones, pues simplemente se podría implementar una legislación y un sistema integrado (de identificación del elector) con el Instituto Nacional Penitenciario y Carcelario INPEC, para facilitar la participación de la población carcelaria en las jornadas electorales.

17 Dhami (2009) aclara que utiliza el término «criminal» [felon] al referirse «a los Estados Unidos, ya que las leyes de privación se refieren a los culpables de una felony (delito grave)», y utiliza el término "preso» [prisoner] al referirse "a otros países, porque las leyes de privación se refieren típicamente a las personas condenadas a penas de prisión» (p. 123).

18 Estos últimos las resguardan para poder adelantar trámites personales o administrativos a favor del recluso. 
materializarse impulsarían la activación de movimientos sociales, recursos administrativos y legislativos que permitirían una mejor dinámica en la concepción de la política pública penitenciaria, así como los recursos económicos y presupuestales necesarios para el progreso del sistema.

En palabras de Dhami (2009), «negar a los presos el derecho a votar puede tener un impacto real en la política de un país» (p. 132), refiriéndose con ello al empoderamiento político en una democracia; y finaliza advirtiendo que «la muerte cívica de los presos es una amenaza para la democracia que debe ser cuestionada (...) puede estimular el debate sobre la reforma penal, así como demostrar un compromiso con los derechos humanos y civiles y la reforma democrática» (p. 134).

Por otro lado, continuando con la referida importancia de la intervención de los tribunales judiciales en asuntos estructurales o de pertinencia de otras autoridades públicas, es así, que en nuestras pesquisas encontramos que en el caso de Argentina, tres tribunales declararon la inconstitucionalidad de las normas que impiden votar a las personas condenadas autorizando a quienes en esa condición lo reclamaban durante las elecciones nacionales de 2011; asimismo, se han tramitado acciones públicas en contra de las normas del Código Penal y de Código Electoral Nacional que consagran las respectivas exclusiones (Filippini y Rossi, 2012). Igualmente, en el 2014, la Corte Suprema Argentina dejó en firme un fallo que reconoce el derecho al voto de los condenados por delitos culposos, «en esencia, sostiene que la condena penal no le resta al condenado los derechos electorales, pues conserva la potestad de elegir a sus representantes» (Espósito, Periódico Tiempo argentino, mayo de 2014).

La Corte Constitucional, en su deber de proteger a una minoría sin representación, ha pasado por alto la necesidad de que esta población en extremo vulnerable, cuente con una representación social o inclusive política, indagando sobre la posibilidad de restablecer el derecho al sufragio de los condenados, y la posibilidad de que sean titulares de las acciones públicas ante el Estado, inspirados en la posibilidad de implementar remedios estructurales que generen alivios ante la sistemática y reiterativa violación de sus derechos fundamentales.

Finalmente, las indagaciones que sustenten esta propuesta, deben apoyarse en el concepto del sufragio universal, declarado en las cartas internacionales de derechos humanos, nuestra constitución nacional, y los sistemas internacionales de derechos humanos. Con la esperada incorporación de la iniciativa en la política pública penitenciaria por los medios ejecutivos o legislativos comunes o por la esperada intervención de los jueces en las políticas públicas del Estado.

\section{CONCLUSIONES}

Se encuentra que la doctrina del $E C /$ se alimenta de las tesis del activismo judicial norteamericano, pero contiene ingredientes propios de la creatividad de la Corte Constitucional Colombiana y sus homólogas latinoamericanas, al punto de ser desarrollada por distintos tribunales judiciales de orden inferior en sede de interpretación de las garantías constitucionales, ante las sistemática y reiterada violación de los derechos fundamentales. El presente estudio determinó, que la declaración del $\mathrm{ECl}$ en el sistema penitenciario colombiano, tiene antecedentes en sentencias de los Estados Unidos sobre graves problemáticas carcelarias, y las cortes latinoamericanas han homologado el litigio de reforma estructural a partir de la aplicación de la doctrina del ECl en Colombia.

A pesar de la sonada influencia de la corte sudafricana en nuestro constitucionalismo actual, no es clara su vinculación directa a la construcción de la doctrina del ECl; sin embargo, es claro que sus medidas enérgicas han generado la aplicación de remedios judiciales para exigir al Estado reformas estructurales con las que se alivien las privaciones a los derechos sociales. Estos precedentes han trascendido a las decisiones de las cortes latinoamericanas.

En Colombia, no se ha dado una discusión comprometida con todos los agentes que integran el sistema, pues desde la óptica democrática de las políticas públicas en asuntos tan graves, es prioritaria la 
participación de los diferentes actores sociales, institucionales y políticos que permitan generar un diagnóstico adecuado, identificando contingencias no reconocidas, y formulando propuestas que permitan construir un proceso serio de transformación y modernización humanizada del tratamiento penitenciario, en términos de eficiencia y eficacia administrativa. Una política pública debe intervenir el conjunto del sistema penitenciario, decantando no sólo el hacinamiento y la resocialización como factor determinante de la crisis carcelaria, reconociendo que se trata de un sector donde debe regularse en un punto medio entre la seguridad y los derechos humanos, adecuándose a las circunstancias actuales del país. Nunca podrá desarrollarse sin el entendimiento de que la política criminal debe ajustarse a las condiciones socioeconómicas reales, atendiendo las circunstancias que permitan superar la administración fallida del sistema penitenciario, mediante la reforma administrativa del sistema carcelario, y la revisión legislativa de las sanciones penales, medidas de aseguramiento, y todo procedimiento que afecte la privación de la libertad.

Es así, que la tensión entre constitucionalismo y la democracia ha generado que los tribunales intervengan en la generación, modificación o sustitución de las políticas públicas, arrogándose para el asunto penitenciario la representación judicial de los reclusos, como sujetos de especial protección constitucional, toda vez que por razones fácticas y de política criminal, les han sido mutilados sus derechos de representación política, al serles restringido su derecho al sufragio electoral, junto a las demás reiteradas y consuetudinarias violaciones a sus derechos humanos.

\section{REFERENCIAS BIBLIOGRÁFICAS}

- Alexy, R. (2003). Tres escritos sobre los derechos fundamentales y la teoría de los principios. Bogotá: (Primera ed.) Universidad Externado de Colombia.

- Castaño, J. (2013). Análisis económico del activismo judicial: el caso de la Corte Constitucional colombiana. Revista Derecho del Estado (31): 119-160.
- Dhami, M. (2009). La política de privación del sufragio a los presos: ¿una amenaza para la democracia? Revista de Derecho (Valdivia), 22(2): 121-135.

- Espósito, N. (14 de Agosto de 2014). Fallo a favor del derecho al voto de los condenados. Tiempo argentino. Recuperado el 22 de Mayo de 2015, de http://tiempo.infonews.com/nota/ 129878/fallo-a-favor-del-derecho-al-voto-de-loscondenados

- Figueroa, E. (2013). Las sentencias del poder judicial sobre amparo. Hábeas corpus, hábeas data y cumplimiento . Lima: Gaceta Jurídica S.A.

- $\quad$ Filippini, L., \& Rossi, F. (2012). Nuevos aportes para el reconocimiento del derecho al voto de las personas condenadas. Revista Jurídica de la Universidad de Palermo, 13(1):187-213.

- Gama, L. (2012). Ilegitimidad democrática del control difuso y presunción de constitucionalidad de las leyes. Sufragio. Revista especializada en derecho electoral, pp. 35-40.

- García, G. (2007). La Corte Constitucional de Sudáfrica y los derechos fundamentales. Revista Iberoaméricana de Derecho procesal constitucional, 8, 175-187.

- Gómez, L. R. (2012). El juez de las políticas públicas: del estado de cosas inconstitucionales en la política económica (Primera ed.). Bogotá D.C.: Pontificia Universidad Javeriana, Facultad de Ciencias Jurídicas: Grupo Editorial Ibañez. Recuperado el 8 de Noviembre de 2014.

- Gómez, M. (enero de 2010). Estado de cosas inconstitucional. Análisis de los motivos de la corte constitucional para su declaratoria. Obtenido de www.upb.edu.co: http://repository. upbbga.edu.co:8080/jspui/handle/123456789/83

- Henao, J. C. (2013). El juez constitucional: un actor de las políticas públicas. Revista de Economía Institucional, pp. 67-102.

- Landa, C., \& Velazco, A. (1993). Constitución Política del Perú 1993. Lima: Fondo Editoria Pontificia Universidad Católica del Perú.

- León, F. (2014). El derecho a la salud en la jurisprudencia del Tribunal Constitucional peruano. Pensamiento Constitucional, pp. 389-420. 
- Liebenberg, S. (2006). Adjudicación de derechos sociales en la Constitución de transformación social de Sudáfrica. Anuario de Derechos Humanos, pp. 53-72.

- López, D. (2004). Teoría impura del derecho. La transformación de la cultura jurídica latinoaméricana. Bogotá: Legis S.A.

- López, G. (2011). El juez constitucional colombiano como legislador positivo: ¿un gobierno de los jueces? Cuestiones Constitucionales, pp. 169-193.

- López, G., \& Gómez, C. F. (2104). La legalización por vía judicial del consumo de la dosis personal de droga: ¿un desafío al sistema democrático en América Latina? Justicia Juris, pp. 102-116.

- Ministerio de Justicia y del Derecho. (2014). Lineamientos para el fortalecimiento de la Política Penitenciaria en Colombia. Dirección de Política Criminal y Penitenciaria, Viceministerio de Política Criminal y Justicia Restaurativa. Bogotá D.C.: CYE Consult. Recuperado el 7 de Abril de 2015, de https://www.minjusticia.gov.co/ Portals/0/sala\%20de\%20prensa/documentos/ Lineamientos $\% 20$ sistema $\% 20$ penitenciario $\% 2$ 0\%20Consulta\%20WEB.pdf

- Mora, S. (Septiembre de 2012). El litigio de la reforma estructural de los tribunales constitucionales como actores políticos. Modificación de condiciones estructurales que desconocen derechos consagrados constitucionalmente. Salamanca, España: Universidad de Salamanca España. Obtenido de http://campus.usal.es/ a c p a / old/sites/defa ult/files / TFM_sandra_mora_castillo.pdf

- Muller, P. (2010). Las Políticas Públicas. Bogotá: Universidad Externado de Colombia.

- Restrepo, H. (2006). Teoría de los derechos humanos y políticas públicas. Tunja: Primera ed. Universidad Pedagógica y Tecnológica de Colombia.

- Rodríguez, C. (2011). Beyond the Courtroom: The Impact of Judicial Activism on Socioeconomic Rights in Latin America. Texas Law Review, 1669-1698.

- Tocora, F. (1997). Política Criminal Contemporánea (Primera ed.). Bogotá: Temis.
- Tole, J. (2006). La teoria de la doble dimensión de los derechos fundamentales en Colombia. El Estado de Cosas Inconstitucionales, un ejemplo de su aplicación. Cuestiones Constitucionales (15):253-316.

- Universidad de Los Andes, Grupo de Derecho de Interés Público. (2010). Situación carcelaria en Colombia. Obtenido de http://www.gidp. uniandes.edu.co

- Uprimny, R., Guzman, D., \& Parra, J. (2013). Penas alucinantes: La desproporción de la penalización de las drogas en Colombia (Primera ed.). Bogotá: Dejusticia.

- Vargas, C. (2003). La garantía de la dimensión objetiva de los derechos fundamentales y labor del juez constitucional colombiano en sede de acción de tutela: El llamado «Estado de cosas inconstitucional». Estudios Constitucionales, pp. 203-228.

\section{REFERENCIAS JURISPRUDENCIALES}

\section{Corte Constitucional de Colombia}

- CConst, T-025/2004, referencia: expediente T653010 y acumulado. M. Cepeda. Obtenido de http://www.corteconstitucional.gov.co/relatoria/ 2004/t-025-04.htm

- CConst, T-153/1998, expediente: T-137.001 y 143.950. E. Cifuentes Obtenido de

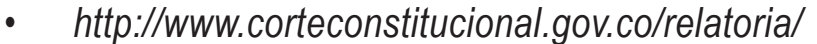
1998/t-153-98.htm

- CConst,, SU-559/1997, expedientes acumulados T-115839 y T-116052. E. Cifuentes Muñoz. Obtenido de http://www.corteconstitucional. gov.co/ relatoria/1997/SU559-97.htm

- CConst,T-068/1998, expedientes T-144.670, T146.357, T- 146.730, T-149.307 y T-149.514 (acumulados), A. Martinez. Obtenido de http:// www.corteconstitucional.gov.co/relatoria/1998/t068-98.htm

- CConst,T-1030/2003, referencia: expediente T751788. C. Vargas Obtenido de http://www. corteconstitucional.gov.co/relatoria/2003/t-103003.htm

- CConst, T-388/ 2013, expedientes T-3526653, T3535828, T-3554145, T-3645480, T-3647294, T-3755661, T-3759881, T-3759882, T-3805761. M 
Calle. Obtenido en http://www.corteconstitucional. gov.co/relatoria/2013/t-388-13.htm

Tribunal Superior de Medellín Tribunal Superior de Medellín

- Tribunal Superior de Medellín, Rad.201200130, A. N. Zapata, J.M. Arteaga y M.P. Yepes. Obtenido de www.usergioarboleda.edu.co/derecho penal/.../tribunal2013/tutela.doc. consultado el 15/Abr/2015.
Tribunal Constitucional del Perú Tribunal Constitucional del Perú

- Tribunal Constitucional del Perú, Exp.№31492004-AC/TC, Bardelli, Gonzales y Vergara. Obtenido de http://www.tc.gob.pe/jurisprudencia/ 2005/03149-2004-AC.html, consultado el 09/Abr./ 2015. 